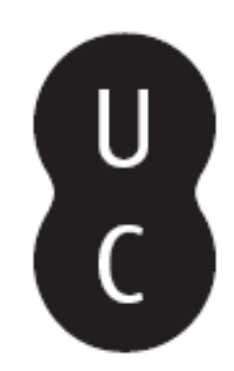

\title{
Pिar TIIIm
}

[Recensão a] TORNADA, Joana de Matos - Nas vésperas da democracia em Portugal: o golpe das Caldas de 16 de Março de 1974
Autor(es):
Vigário, Rafael Marques
Publicado por: Centro de História da Sociedade e da Cultura
URL persistente:
URI:http://hdl.handle.net/10316.2/39592
DOI:
DOI:http://dx.doi.org/10.14195/1645-2259_9_18

Accessed : $\quad$ 26-Apr-2023 14:16:23

A navegação consulta e descarregamento dos títulos inseridos nas Bibliotecas Digitais UC Digitalis, UC Pombalina e UC Impactum, pressupõem a aceitação plena e sem reservas dos Termos e Condições de Uso destas Bibliotecas Digitais, disponíveis em https://digitalis.uc.pt/pt-pt/termos.

Conforme exposto nos referidos Termos e Condições de Uso, o descarregamento de títulos de acesso restrito requer uma licença válida de autorização devendo o utilizador aceder ao(s) documento(s) a partir de um endereço de IP da instituição detentora da supramencionada licença.

Ao utilizador é apenas permitido o descarregamento para uso pessoal, pelo que o emprego do(s) título(s) descarregado(s) para outro fim, designadamente comercial, carece de autorização do respetivo autor ou editor da obra.

Na medida em que todas as obras da UC Digitalis se encontram protegidas pelo Código do Direito de Autor e Direitos Conexos e demais legislação aplicável, toda a cópia, parcial ou total, deste documento, nos casos em que é legalmente admitida, deverá conter ou fazer-se acompanhar por este aviso.

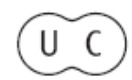



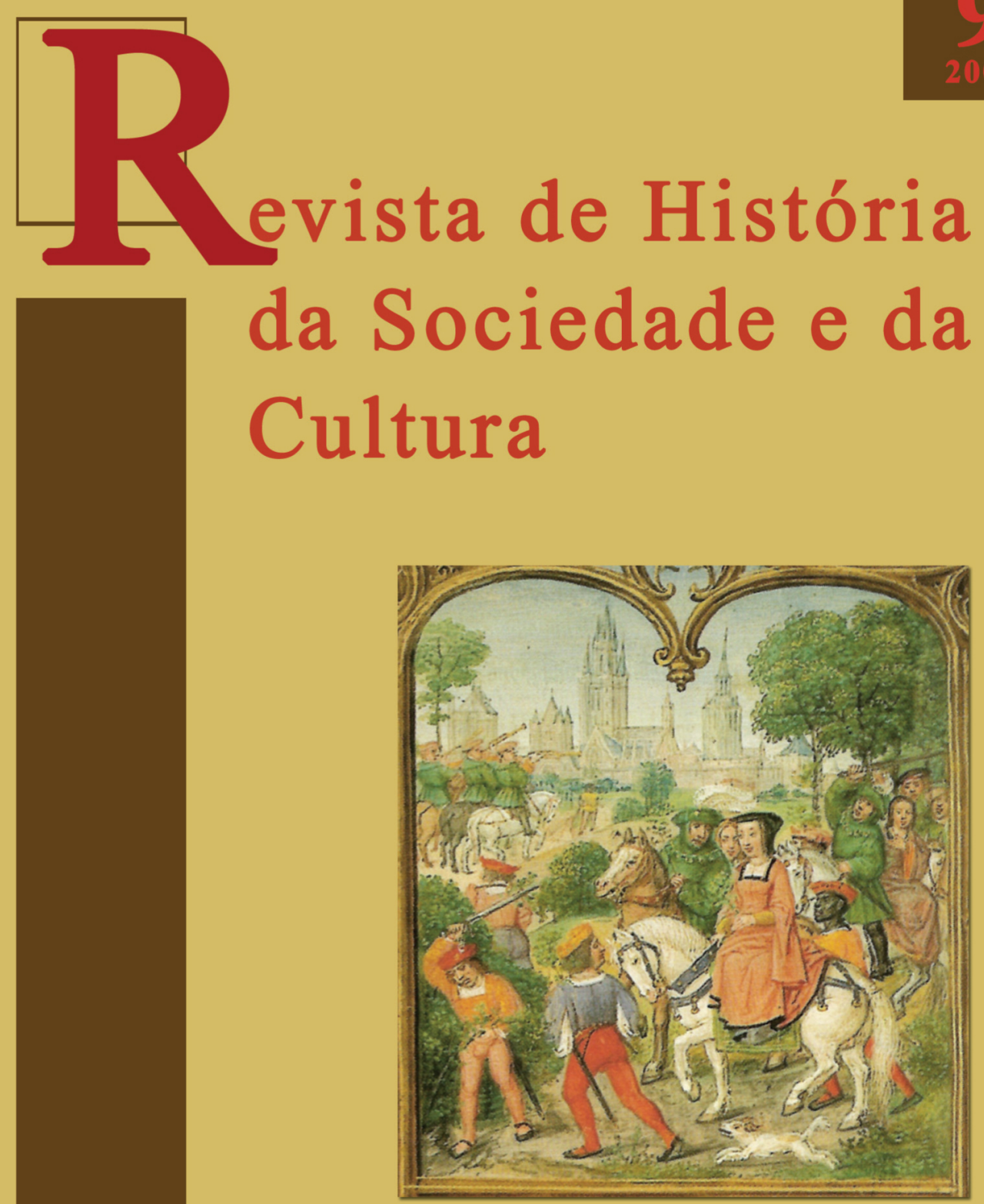

Centro de História da Sociedade e da Cultura Universidade de Coimbra

Coimbra 
O seu maior interesse no panorama historiográfico das invasões francesas, reside no facto de deslocar o núcleo da acção da segunda invasão francesa para o centro do país, muitos quilómetros a Sul do Porto, para onde, apenas a espaços e de forma tímida, os estudos de investigação e, consequentemente, de síntese, se deslocam. Fá-lo, não só ao descrever a ocupação das regiões de Albergaria-a-Velha e Estarreja, a resistência que se fez ao Sul desse rio entre Aveiro e Águeda, mas também ao dar destaque a Coimbra, sublinhando o papel que o seu governador e o batalhão académico tiveram na organização da defesa do rio Vouga e da preparação logística para a chegada do exército de Wellesley.

\section{Alexandre Pinto}

Doutorando do Instituto de Investigação Interdisciplinar - Universidade de Coimbra alexpinto@iol.pt

TORNADA, Joana de Matos - Nas vésperas da democracia em Portugal: o golpe das Caldas de 16 de Março de 1974. Coimbra: Edições Almedina, 2009, 312 p.

Nas vésperas da democracia em Portugal é o título da recente obra de investigação de Joana de Matos Tornada e resultado da sua dissertação de Mestrado em História, especialidade em História Contemporânea, apresentada na Faculdade de Letras da Universidade de Coimbra. Este livro marca a estreia da autora, depois de um curso de Mestrado conjunto entre as universidades de Coimbra e de Uppsala, na Suécia, designado "The twisted road to democracy". Apresenta-se, por isso, enriquecido e devedor de vários contributos de renome, entre os quais, em Coimbra, o dos professores doutores Rui Cunha Martins (orientador da dissertação), Fernando Catroga e Maria Manuela Tavares Ribeiro, e em Uppsala, de John Rogers e Lars M. Anderson.

Conforme o título indica, este trabalho debruça-se sobre Golpe das Caldas da Rainha de 16 de Março de 1974. Ao sistematizar os conhecimentos disponíveis sobre esta temática, a autora procurou colmatar uma lacuna na historiografia portuguesa, recorrendo à documentação governamental, 
memórias publicadas, à imprensa contemporânea, mas também a entrevistas que a própria conduziu a alguns dos principais militares envolvidos. Tudo, feito com um grande rigor analítico, combatendo o carácter dispersivo e muitas vezes impreciso das fontes.

Contudo, esta não é a história do Golpe das Caldas. Na verdade, ao leitor é sugerido um texto que se propõe formular e desconstruir hipóteses sobre as motivações de todos os envolvidos nos acontecimentos que antecederam a saída da coluna sublevada do Regimento de Infantaria 5, as estratégias que poderão ter precipitado os acontecimentos, as razões do insucesso da sublevação do quartel das Caldas da Rainha, as diferentes visões do Golpe das Caldas veiculadas pelo Governo, pelo MOFA, ou pela imprensa, e ainda as representações do Golpe de 16 de Março construídas na sua posteridade.

O livro está dividido em três partes, sendo a primeira "Os comprometidos do 16 de Março". Aqui revelam-se as raízes e motivações dos militares envolvidos, as suas expectativas, dúvidas e motivações. A segunda parte, "O Golpe de 16 de Março de 1974", é a mais extensa, e aqui são analisados com grande pormenor, seguindo essencialmente um critério cronológico, os dez dias que antecederam o golpe e o próprio dia 16, para depois procurar o sentido do 16 de Março, seguindo três linhas de pesquisa: a reacção do governo, a luta do MOFA e a representação do golpe pela imprensa, que expõem as diferentes visões do mesmo, produzidas no seu contexto. A terceira parte intitulada "O epílogo do 16 de Março", apresenta as percepções e opiniões dos protagonistas posteriores aos eventos.

Em anexo, o livro apresenta ainda muita informação. Alguma dela traçada pela autora: uma cronologia dos acontecimentos ocorridos entre 2 e 14 de Março de 1974; um diário do golpe; para além de dois mapas, um representando os acontecimentos ocorridos em várias unidades militares no dia 15 de Março de 1974, outro, fazendo o mesmo com os movimentos ocorridos no dia seguinte. Outra parte está dedicada à reprodução de documentos oficiais, a saber: "Fita do tempo dos acontecimentos de 16Mar74, no RI15”, emanado do Quartel-General da Região Militar de Tomar; "Relatório de situação, segurança interna: incidentes de 16 e 17Mar", pelo comandante do RI7; “Acontecimentos do dia 16/17 Mar 74”, Major Guimarães; "Relatório da acção em consequência dos acontecimentos 
registados no RI 5 em 16Mar74", EPC Santarém; "Relação dos oficiais do QP que seguiram para Lisboa em 16/Mar/74", Regimento de Infantaria 5; "Relação de oficiais do Q. C. que seguiram para Lisboa em 16/Mar/74", Regimento de Infantaria 5; "Relação dos Furriéis Milicianos e 1. ${ }^{\circ}$ s Cabos Milicianos que marcharam para Santa Margarida em 16/Mar/74, Regimento de Infantaria 5; "Mensagem Confidencial", CEM/QG/RME; "Rel. Cir. De Oper. N. ${ }^{\circ}$ 4/74, Sublevação de Oficiais no Regimento de Infantaria n. ${ }^{\circ} 5$ em Caldas da Rainha", Tenente José Augusto Pascoal Pires; "Relatório de Operações n. ${ }^{\circ}$ 2/74", Comando-Geral da GNR; "Resumo de Notícias n. ${ }^{\circ}$ 1/74", Batalhão 2 (GNR).

Como é conhecido, este golpe não teve o sucesso que os seus promotores desejavam, pelo que é difícil medir de que forma a intentona das Caldas provocou o declínio do Estado Novo. Para isso também contribuiu o facto deste movimento não ter sido promovido nem se ter apoiado por nenhuma estrutura política, económica ou social predefinida. Pelo contrário, estava mais ligado às emoções e pensamentos do que a quaisquer estratégias políticas personalizadas. Os cerca de 200 militares que participaram na sublevação do RI5, precipitaram-se, porque avançaram perante a precipitação dos oficiais de Lamego, mas também porque alguns oficiais julgavam que o regime estava frágil e sentiam a premência de uma acção militar, onde uma simples companhia poderia abanar o regime e derrubá-lo. Contudo, o Golpe das Caldas não deixou de funcionar como catalizador do que aconteceria no mês seguinte, ao pôr a nu a inaptidão do regime para manter a ordem e disciplina nas Forças Armadas, sintoma da rápida desagregação de um dos seus pilares, exercendo ainda, sobre o MFA, uma pressão no sentido da irreversibilidade de um desenlace violento.

Por tudo isto, mas sobretudo pela sistematização percursora, pela capacidade de análise e problematização, bem como pelo levantamento de novos caminhos de investigação, esta obra é essencial para a compreensão da história recente do nosso país e, em especial, para descortinar o tortuoso caminho da imposição da democracia na vida política e em toda a sociedade portuguesa.

\section{Rafael Marques Vigário}

Professor de História do Ensino Básico e Secundário

r_vigario@iol.pt 